\title{
Inhibition of Akt signaling in hepatoma cells induces apoptotic cell death independent of Akt activation status
}

\author{
Francesca Buontempo • Tulin Ersahin • Silvia Missiroli • Serif Senturk • Daniela Etro • \\ Mehmet Ozturk • Silvano Capitani • Rengul Cetin-Atalay • Maria Luca Neri
}

Received: 1 April 2010 /Accepted: 24 June 2010/Published online: 14 July 2010

(C) Springer Science+Business Media, LLC 2010

\begin{abstract}
Summary The serine/threonine kinase Akt, a downstream effector of phosphatidylinositol 3-kinase (PI3K), is involved in cell survival and anti-apoptotic signaling. Akt has been shown to be constitutively expressed in a variety of human tumors including hepatocellular carcinoma (HCC). In this report we analyzed the status of Akt pathway in three HCC cell lines, and tested cytotoxic effects of Akt pathway inhibitors LY294002, Wortmannin and Inhibitor VIII. In Mahlavu human hepatoma cells Akt was constitutively activated, as demonstrated by its Ser 473 phosphorylation, downstream hyperphosphorylation of BAD on Ser136, and by a specific cell-free kinase assay. In contrast, Huh7 and HepG2 did not show hyperactivation when tested by the same criteria. Akt enzyme hyperactivation in Mahlavu was associated with a loss of PTEN protein expression. Akt signaling was inhibited by the upstream kinase inhibitors, LY294002, Wortmannin, as well as by the specific Akt Inhibitor VIII in all three
\end{abstract}

Francesca Buontempo and Tulin Ersahin have contributed equally to this work.

Electronic supplementary material The online version of this article (doi:10.1007/s10637-010-9486-3) contains supplementary material, which is available to authorized users.

F. Buontempo $\cdot$ S. Missiroli $\cdot$ D. Etro $\cdot$ S. Capitani $\cdot$

M. L. Neri $(\bowtie)$

Dipartimento di Morfologia ed Embriologia,

Sezione di Anatomia Umana, Signal Transduction Unit,

Universita' di Ferrara,

via Fossato di Mortara 66,

44100 Ferrara, Italy

e-mail: luca.neri@unife.it

T. Ersahin $\cdot$ S. Senturk $\cdot$ M. Ozturk $\cdot$ R. Cetin-Atalay $(\square)$

Department of Molecular Biology and Genetics,

Bilkent University,

TR-06800 Ankara, Turkey

e-mail: rengul@bilkent.edu.tr hepatoma cell lines. Cytotoxicity assays with Akt inhibitors in the same cell lines indicated that they were all sensitive, but with different IC50 values as assayed by RT-CES. We also demonstrated that the cytotoxic effect was through apoptotic cell death. Our findings provide evidence for its constitutive activation in one HCC cell line, and that HCC cell lines, independent of their Akt activation status respond to Akt inhibitors by apoptotic cell death. Thus, Akt inhibition may be considered as an attractive therapeutic intervention in liver cancer.

Keywords Akt $\cdot$ PI3K $\cdot$ PTEN $\cdot \mathrm{HCC} \cdot \mathrm{LY} 294002$.

Inhibitor VIII $\cdot$ Wortmannin $\cdot$ RTCES

\section{Introduction}

Hepatocellular carcinoma (HCC) is one of the most common cancers worldwide occurs in patients with chronic viral hepatitis and cirrhosis at a high rate (3-5\% annually) and is a major cause of morbidity and mortality in patients with advanced liver disease [1]. In healthy individuals, liver is a quiescent organ and adult hepatocytes are nondividing cells under normal physiological conditions. However, chronic liver injury due to viral diseases, exposure to chemicals and other environmental or host factors results in extensive cell death and consequently hepatocyte proliferation [2]. Chronic cell death in liver leads to a state where continuous hepatocyte regeneration is observed as a result of the inflammatory response. Continuous cycles of liver cell death and proliferation induce many cell signaling pathways including cell survival pathways such as Akt [3, 4]. Knowledge on the signaling pathways and the alterations involved in HCC is extending, however their role in molecular targeted therapy still remains to be described. 
The most promising molecular targets in the generation of new chemotherapy agents are the protein kinases, including those in the PI3K/Akt pathway. The Akt pathway is involved in many cancers, as well as HCC development, through its activation by EGF or IGF signaling or the constitutive activation of Akt proteins or the inactivation of PTEN tumor suppressor [5-8]. The serine/threonine kinase Akt is a wellcharacterized downstream target of PI3K and resides within the cytoplasm in an inactive state, but binding of PtdIns $(3,4,5) \mathrm{P} 3$ to its pleckstrin homology $(\mathrm{PH})$ domain recruits Akt to the plasma membrane and enables its activation by phosphorylation on the C-terminal hydrophobic tail [9]. Once activated, signaling through Akt can be propagated to a diverse array of substrates. Activated Akt is known to inhibit apoptosis through its ability to phosphorylate several targets, including BAD, FoxO transcription factors, Raf- 1 and caspase-9, which are critical for cell survival [9]. Moreover, the tumor suppressor protein PTEN prevents Akt activation by acting as a lipid phosphatase on the PI3K product PtdIns $(3,4,5) \mathrm{P} 3$. Akt pathway hyper-activation has been reported due to the loss of tumor suppressor protein PTEN function through mutations, deletions, or epigenetic silencing $[10,11]$. The PTEN gene is the second most frequently modified tumor suppressor gene, and is related to many cancers including brain, bladder, breast, prostate, endometrial and liver cancer [10-12].

In primary liver carcinoma, one of the major pathogenic mechanisms resides in the activated intracellular signal transduction caused by oncogenes and the tumor suppressor gene dysfunction that stimulates cell-cycle progression and enhance cell survival [13]. Despite this much information, the behavior and relevance of the Akt pathway in HCC and its therapeutic potential remain to be further elucidated. Since liver cancer usually develops on the background of chronic liver disease, conventional anticancer therapies are not effective. Moreover, the chemotherapeutics currently in use are non-selective cytotoxic drugs that can lead to systemic side effects in HCC patients with compromised liver function. Recently, Sorafenib, a multikinase inhibitor acting through VEGFR and PDGFR of the Raf kinase pathway, was approved for hepatocellular carcinoma treatment [4]. The Sorafenib Hepatocellular Carcinoma Assessment Randomized Protocol (SHARP) three-year clinical trial included 602 advanced-stage HCC patients (ClinicalTrials.gov number, NCT00105443) [4]. The average survival rate for the group taking Sorafenib was 10.7 months, and that for the group taking the placebo was 7.9 months. For the Sorafenib group a one-year survival rate of $44 \%$ was observed, whereas it was $33 \%$ for the placebo group. FDA- and EU- approved chemotherapeutic Sorafenib thus prolongs median survival and the time to progression by nearly three months in patients with advanced hepatocellular carcinoma. Therefore FDA and EU approved chemotherapeutic Sorafenib prolongs median survival and the time to progression by nearly 3 months in patients with advanced hepatocellular carcinoma. Therefore, there is a need for new liver cancer specific drugs based on the molecular mechanisms involved in liver carcinogenesis.

In this study, we investigated the Akt activation status in HCC cell lines the differential effects of three Akt pathway inhibitors and the extent of the inhibition of Akt signaling as a major molecular mechanism in determining inhibitorinduced apoptosis in these cells. The Akt pathway can be blocked by cell line specific doses of pathway inhibitors. Therefore, our findings suggested that PI3K/Akt could represent an attractive target mitigating in liver cancer.

\section{Materials and methods}

\section{Materials}

DMEM (cat.12-614F), FCS (cat.DE 14-801F), antibiotics (cat.DE 17-602E), glutamine and non essential amino acids (cat.BE 13-114E) were from Lonza (Milan). Calnexin, $\beta$ actin antibody, and Sulforhodamine B (SRB) (cat.86183$5 \mathrm{~g}$ ) were from Sigma (St. Louis, MO). Lumi-Light detection kit (cat.12 015 196001) was from Roche M.B. (Germany). Akt Inhibitor VIII (cat.124018), Wortmannin (cat. BML-ST415-0005) and LY294002 (cat.440202) were from Calbiochem (La Jolla, CA). The DMSO concentration for drug solubilization was always less than $1 \%$ in the cell culture medium.

The Akt Antibody (cat.610861) was from BD Transduction Laboratories (Franklin Lakes, NJ) and anti-p-473Ser Akt (cat.587F11), anti-BAD (cat.185D10), anti-p-BAD (cat.\#9292), recGSK3 $\alpha / \beta$ fusion protein (cat.\#9237 L), anti-p-GSK3 $\alpha / \beta$ (cat.\#9331 L), anti-PTEN and anti-PARP (cat.46D11) antibodies were from Cell Signaling (Danvers, MA). The immunoprecipitation matrix (cat.sc-45042) was from Santa Cruz Biotechnology (Santa Cruz, CA).

\section{Cell culture}

Hepatoma cells (Huh7, HepG2, Mahlavu) were cultured at $37^{\circ} \mathrm{C}, 5 \% \mathrm{CO}_{2}$ in standard medium (2 mML-Glutamine, $0.1 \mathrm{mM}$ NEA, 1xPS in DMEM) with $10 \%$ FCS.

Western blotting analysis

Proteins, from cells grown to $60-70 \%$ confluence, were separated on $10 \%$ SDS-PAGE, transferred onto nitrocellulose membranes and visualized as described previously [14]. 
Akt kinase activity assay

Total homogenates from cells were resuspended in $50 \mathrm{mM}$ Tris-HCl pH 7.4, 1 mM EDTA, 1 mM EGTA, $150 \mathrm{mM}$ $\mathrm{NaCl}, 1 \%$ Triton $\mathrm{X}-100,0.1 \%$ SDS plus phosphatase and proteases inhibitors. IP was performed according to the manufacturer's instruction. Akt IP was resuspended in $20 \mathrm{mM}$ HEPES pH 7.4, $10 \mathrm{mM} \mathrm{MgCl}_{2}$ and $10 \mathrm{mM} \mathrm{MnCl}_{2}$. The reaction was started by incubating $10 \mu \mathrm{l}$ IP, $100 \mu \mathrm{M}$ ATP and $1 \mu \mathrm{g}$ recGSK $3 \alpha / \beta$ for $40 \mathrm{~min}$ at RT, and then stopped by $1 \mathrm{M}$ Tris- $\mathrm{HCl} \mathrm{pH} 6.8,8 \%$ SDS, 40\% glycerol, $20 \% \beta$-ME. GSK $3 \alpha / \beta$ phosphorylation was detected by western blotting.

NCI-60 Sulforhodamine B (SRB) cytotoxicity assay

The cytotoxicities of LY294002, Akt Inhibitor VIII and Wortmannin were tested as previously described [15]. Hepatoma cells (5000) were inoculated into 96 well plates, $100 \mu \mathrm{l} /$ well. Next day, inhibitors with the indicated concentrations were applied in a total of $200 \mu \mathrm{l}$ of medium. After $72 \mathrm{~h}$ of treatment, cells were fixed by cold $10 \%(\mathrm{w} / \mathrm{v})$ TCA and then the wells were washed and dried. One hundred $\mu$ of $0.4 \%$ SRB dye was applied to each well and incubated at RT for $10 \mathrm{~min}$ then removed and wells were dried. SRB dye was solubilized in $200 \mu \mathrm{l}$ $10 \mathrm{mM}$ Tris-Base and the absorbance was measured at $515 \mathrm{~nm}$.

Real-time cell growth surveillance by cell electronic sensing

Hepatoma cells $(2000$ cell/well in $150 \mu \mathrm{l})$ were inoculated into 96 E-Plates (Roche) containing $50 \mu \mathrm{l}$ medium/ well. Proliferation was monitored in real-time cell electronic sensing RT-CES (xCELLigence-Roche Applied Science), and the cell index (CI) was measured every $30 \mathrm{~min}$ for $24 \mathrm{~h}$ [16]. Next day, $100 \mu \mathrm{l}$ medium was discarded and $50 \mu \mathrm{l}$ fresh medium was added to each well. Inhibitors with indicated concentrations were applied to $150 \mu \mathrm{l}$ of medium. CI values were taken every $10 \mathrm{~min}$ for $4 \mathrm{~h}$ to visualize the fast drug response and then every $30 \mathrm{~min}$ to visualize the long-term drug response. Impedance measurements are displayed as Cell Index (CI) values and the effect of the inhibitors on cell growth is calculated as $\mathrm{CI}_{\mathrm{DRUG}} / \mathrm{CI}_{\mathrm{DMSO}}$. When the cells adhered to electrodes on the bottom of the wells, CI values increased in parallel to the cell growth due to the insulating properties of the cell membrane. As the number of cells covering the electrodes increases the electrical impedance $(Z)$ increased $\left(Z_{0}=0--->Z=Z_{\text {cell }}\right)$.
Fluorescence microscopy

Cells were seeded at $3 \times 10^{4}$ cells $/ \mathrm{cm}^{2}$ on coverslips, allowed to grow for $24 \mathrm{~h}$, as indicated in the figure legends, then washed twice with PBS and fixed with $4 \%$ paraformaldehyde. Subsequently, cells were washed once more with PBS and stained with $0.5 \mathrm{mg} / \mathrm{ml}$ DAPI. Preparations were dehydrated with increasing concentrations of ethanol and embedded in glycerol containing the antifading agent to be analyzed with Zeiss Axiophot epifluorescence microscope coupled with a Photometric Cool Snap CCD camera for image acquisition. The percentage of apoptotic cells was determined by counting fragmented nuclei in a minimum of 4 fields containing at least 150 cells. These experiments were performed in triplicate. As a positive control for apoptosis, cells were treated with $100 \mathrm{ng} / \mathrm{ml}$ Doxorubicine.

\section{RT-PCR}

Total RNA was isolated with NucleoSpin RNA II Kit (MN, Germany). cDNAs synthesized from $4 \mu \mathrm{g}$ RNA with RevertAid kit (MBI Fermentas, Lithuania) were amplified by PCR with the primers (PTEN: intron-3-F_5'-AAAGATT CAGGCAATGTTTGTT-3', intron-4-R_5'-TCTCACTCGA TAATCTGGATGAC-3', exon-4-F_5'-GACATTATGA C A C C G C C A A A - 3', ex on - 5 - R _5 ' - T T C G TCCCTTTCCAGCTTTA-3', exon-7-F_5'-CGACGGGAA GACAAGT TCAT-3', exon-8-R_5'A GGT T T CCTCTGGTCCTGGT-3', and GAPDH: F-5'-GGCTGA GAACGGGAAGCTTGTCAT-3' and R-5'CAGCCTTCTC CATGGTGGTGAAGA-3').

\section{Results}

Akt hyperphosphorylation in Mahlavu HCC cells

Hyperactivation of Akt was previously reported in $\mathrm{HCC}$ [17]. Therefore, we sought first to analyze the Akt levels and its serine-473 phosphorylation in hepatoma cells. Akt total amount seems comparable albeit a slight higher expression could be observed in Mahlavu cells when compared to Huh7 and HepG2 cells (Fig. 1a). In addition, significant Akt phosphorylation was detectable in Mahlavu cells, whereas only a slight Akt phosphorylation was detectable in HepG2 and Huh7 cells under native conditions.

Therefore, our initial observation suggested that the poorly differentiated Mahlavu cell line might have hyperactivated Akt signaling in comparison to the well-differentiated HCC 
a

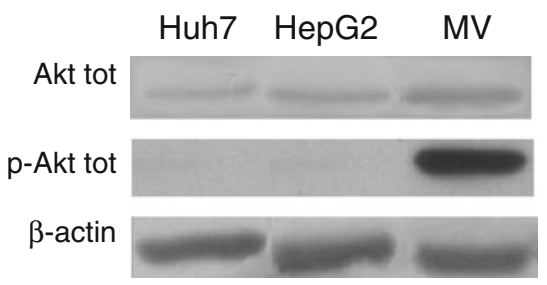

b
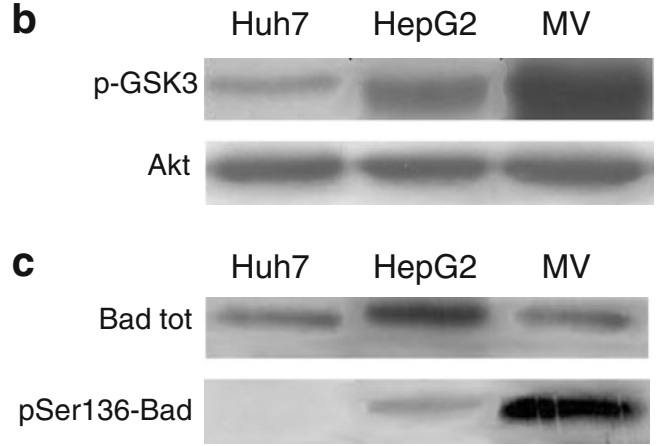

Fig. 1 Akt activity analysis in HCC cell lines. a Western blot analysis of untreated Huh7, HepG2, and Mahlavu cell lines, detected with anti Akt antibody or anti-p-Akt antibody. b Kinase assay on the fusion protein of GSK $3 \alpha / \beta$ added to the reaction mixture as an exogenous substrate. As a control for equal loading, samples of immunoprecipitated Akt for the kinase assay were used. c Western blot analysis of untreated HCC cell lines was performed with anti-total BAD antibody or anti-p-BAD antibody. $20 \mu \mathrm{g}$ of proteins were loaded for each lane. Data given here are representative of three independent experiments. SDS are less than $10 \%$. The Mahlavu cell line displays high a Akt phosphorylation level and the highest enzymatic activity tested on both exogenous $(\mathrm{GSK} 3 \alpha / \beta)$ and endogenous (BAD) substrate

cell lines; Huh7 and HepG2 [18]. To further assess whether Akt hyperphosphorylation in Mahlavu cells is related to the hyperactivation of its kinase enzymatic activity, we performed a kinase assay on the fusion protein GSK3 containing Akt target-phosphorylation residues. The results of this assay (Fig. 1b) showed the presence of a very low intrinsic activity in Huh7 cells, an intermediate activity in HepG2 cells but a very high kinase activity in Mahlavu cells. As a control for equal loading, samples of immunoprecipitated total Akt for the kinase assay were used. These data correlate very well with those obtained by western blot data on p-Akt (Fig. 1a).

We sought to further verify Akt pathway activation on a native target of Akt. To this end, we analyzed the phosphorylation status of $\mathrm{BAD}$, a well-known protein downstream of Akt, whose phosphorylation prevents cells from undergoing apoptosis and confers them a proliferative advantage. The p-BAD antibody used in our study was specific to the Ser136 target of Akt kinase. In this way we excluded the possibility of BAD being phosphorylated by other kinases such as Erk-p90RSK kinase, which targets Ser122 [19]. pSer136-BAD was absent in Huh7 cells, and barely detectable in HepG2 cells, whereas a high level of pSer136-BAD was detected in Mahlavu cells (Fig. 1c).
Interestingly, total $\mathrm{BAD}$ protein levels were not equal in the cell lines analyzed although each lane contained $20 \mu \mathrm{g}$ of total cell lysate, in particular Mahlavu showed lower BAD protein levels than HepG2 (Fig. 1c). However, we observed an intense phosphorylation by endogenous $\mathrm{BAD}$ in this cell line, which might explain the faint pSer136-BAD band in HepG2.

Determination of IC50 values for the HCC cells with SRB cytotoxicity assay

After the analysis of the hyperphosphorylation state of the Akt protein in well differentiated Huh7, HepG2 cells and poorly differentiated Mahlavu cells under native conditions, we decided to see the effect of PI3K inhibitors (LY294002, Wortmannin) and the specific Akt inhibitor (Inhibitor VIII) on this signaling pathway. Akt Inhibitor VIII selectively prevents Akt1 and Akt2 activity through pleckstrin homology (PH) domain [20, 21].

Initially we assessed their cytotoxicity by NCI-60 conventional Sulforhodamine B assay that was performed in quadruplicate and for 5 different concentrations following the NCI's drug screening protocol. The inhibitory effect of each drug of treatment was plotted (Fig. 2). IC50 values were calculated from these graphs for 24,48 , and $72 \mathrm{~h}$ (Fig. 2). IC50 values of LY294002 were $3.65 \mu \mathrm{M}$, $25.03 \mu \mathrm{M}$ and $7.19 \mu \mathrm{M}$ for $24 \mathrm{~h}$ and $3.75 \mu \mathrm{M}, 5.82 \mu \mathrm{M}$ and $8.71 \mu \mathrm{M}$ for $72 \mathrm{~h}$ in Huh7, HepG2 and Mahlavu cell lines, respectively. For Wortmannin IC50 values in Huh7, HepG2 and Mahlavu cell lines were $26.07 \mu \mathrm{M}, 29.23 \mu \mathrm{M}$ and $20.19 \mu \mathrm{M}$ for $24 \mathrm{~h}$ and $17.78 \mu \mathrm{M}, 11.27 \mu \mathrm{M}$ and $36.88 \mu \mathrm{M}$ for $72 \mathrm{~h}$, respectively. For $24 \mathrm{~h}$, the IC50 values of Inhibitor VIII were $4.42 \mu \mathrm{M}$ and $17.16 \mu \mathrm{M}$ for Huh7 and HepG2, while there was not a significant inhibition observed in Mahlavu with NCI-60 assay. For 72 h, the IC50 values of Inhibitor VIII were $5.27 \mu \mathrm{M}, 4.48 \mu \mathrm{M}$ and $9.04 \mu \mathrm{M}$ for Huh7, HepG2 and Mahlavu cells, respectively.

Real-time, dynamic monitoring of cell growth in HCC cells treated with the inhibitors

In order to further analyze if the growth inhibition of HCC cells is permanent or temporary, we used a novel cell surveillance system to monitor real-time, dynamic changes in cell growth based on the electrical impedance measurement technique. The RT-CES system allowed us to monitor the effects of LY294002, Wortmannin, and Inhibitor VIII on the hepatoma cells by a label-free and a real-time native approach. The proliferation and cytotoxicity of the inhibitors were followed by real-time through electronic cell sensors, integrated in the bottom of the 96 E-Plates in triplicates with 5 different concentrations $(40 \mu \mathrm{M}, 20 \mu \mathrm{M}$, $10 \mu \mathrm{M}, 5 \mu \mathrm{M}, 2.5 \mu \mathrm{M}$ ) (Fig. 3). When normalized to 


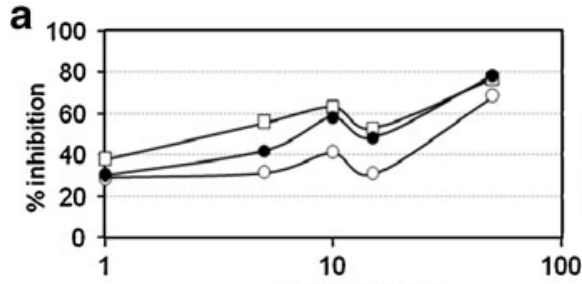

\section{b}

$\operatorname{LY} 294002(\mu \mathrm{M})$
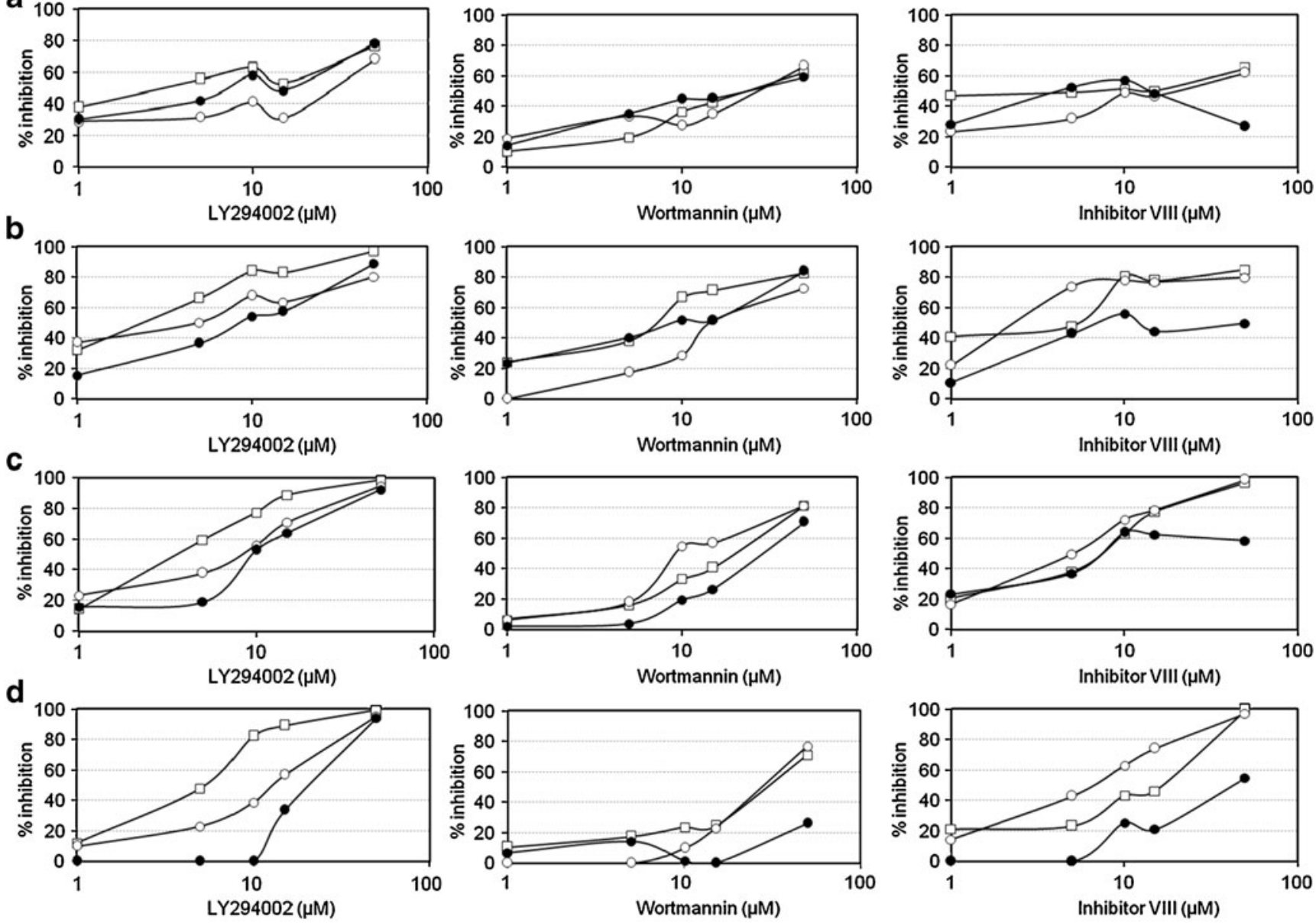

Fig. 2 Inhibitory effects of LY294002, Wortmannin and Akt Inhibitor VIII on HCC cell growth. \% inhibition of cell growth after a 24, b 48, c 72 and d 96 hours of treatment with the inhibitors. Sulforhodamine B (SRB) colorimetric assay was performed in quadruplets with 5 different concentrations $(50 \mu \mathrm{M}, 15 \mu \mathrm{M}, 10 \mu \mathrm{M}, 5 \mu \mathrm{M}, 1 \mu \mathrm{M})$ represented with error bars (Supplementary Figs. 1-3). The growth

inhibitory effect for shorter exposure is relevant also for low concentrations. At longer exposure times growth inhibition requires higher drug concentrations. IC50 values were calculated based on the logarithmic regression line fitted on the \% inhibition vs. $\log$ (concentration) graph, Huh7 ( $\square-)$, HepG2 (-م-), Mahlavu ( $\bullet-)$

DMSO treated cell proliferation curves the cell growth plots demonstrated the concentration- and time-dependent cytotoxic effect of the inhibitors. In addition to provide also a visual demonstration of the effects of these drugs on these cells we treated cells with inhibitors and show their morphological changes by light microscope images at 24 and 48 hours in parallel with the RT-CES experiments with IC50 of 24 hours concentrations (Fig. 3b).

High dose treatment of LY294002 $(40 \mu \mathrm{M})$ suppressed cell growth permanently after $8 \mathrm{~h}$ and continuing up to $84 \mathrm{~h}$ in Huh7 and Mahlavu cell lines. Lower doses $(5 \mu \mathrm{M}$, $2.5 \mu \mathrm{M}$ ) of LY294002 had a minor effect on cell growth for up to $48 \mathrm{~h}$ but then the cells resumed growth, especially in the case of the Mahlavu cell line. With Inhibitor VIII treatment, cells responded similarly as to LY294002 exposure although Inhibitor VIII appeared more effective at short exposure times. Wortmannin treatment was effective in inhibiting cell growth only for about $24 \mathrm{~h}$ and then

the cells gradually resumed normal growth. This real-time dynamic continuous analysis of cell growth and toxicity was essential to determine the optimal time points for performing biochemical endpoint assays. The continuous, dynamic analysis of cell growth of LY294002, Wortmannin and Akt Inhibitor VIII treated Huh7 and Mahlavu cells supported the time- and concentration-dependent effects of the three inhibitors on HCC cells as shown in Fig. 2.

We also analyzed Akt enzyme activity in the presence of inhibitors. The IC50 values of $72 \mathrm{~h}$ for LY294002, Wortmannin and Akt Inhibitor VIII were used to assess the effects of drug treatments on Akt kinase activity in HCC cell lines by a specific kinase assay using the fusion protein fusion protein of GSK $3 \alpha / \beta$ as substrate similarly to that of Fig. 1b. Our results demonstrated the inhibitory effect of the three drugs on the kinase activity of the Akt protein, when compared to the kinase assay under native conditions. In all cases no Akt phosphorylation activity was 

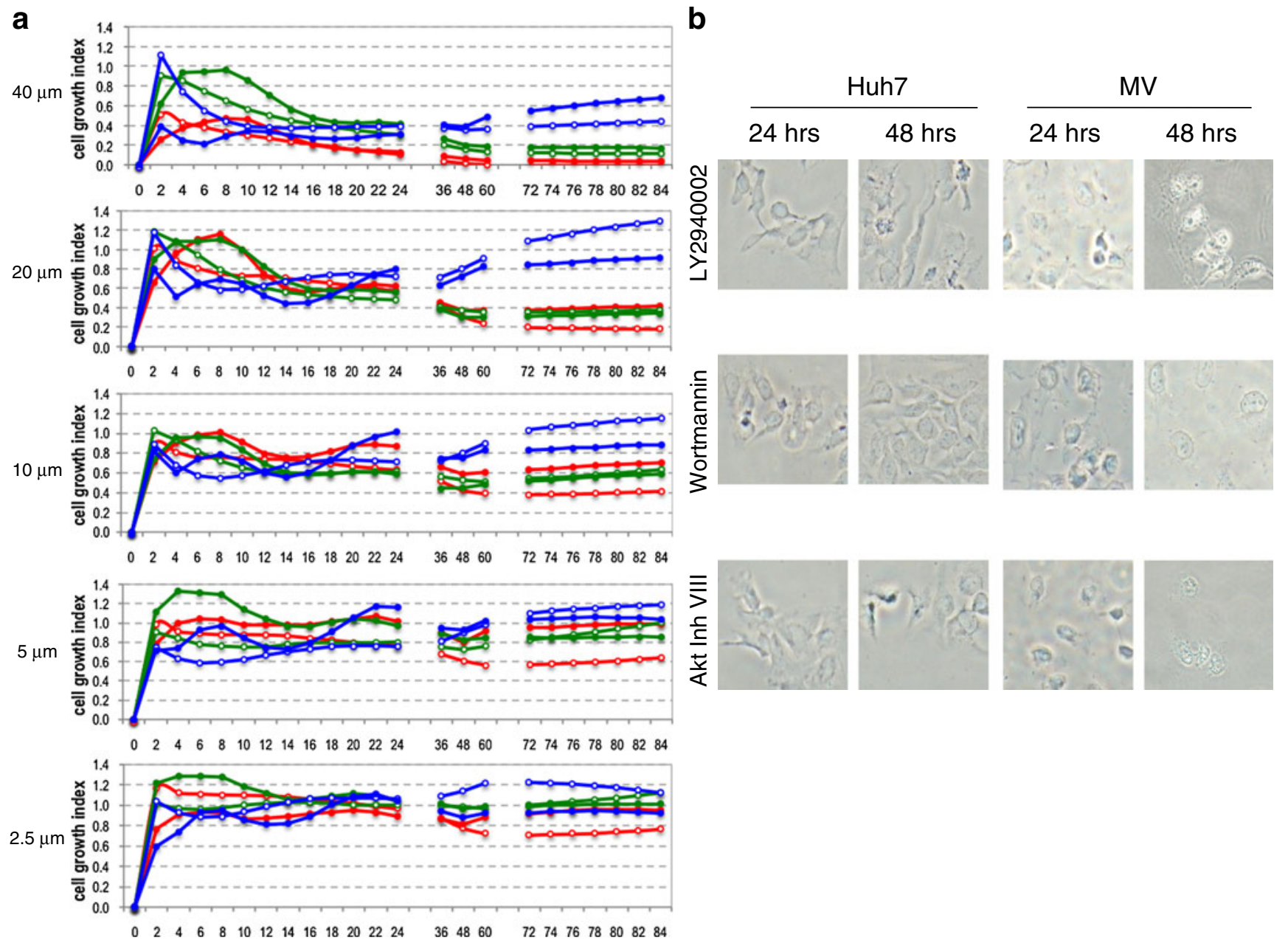

Time (hrs)

Fig. 3 Cell growth of LY294002, Wortmannin and Akt Inhibitor VIII treated Huh7 and Mahlavu cells. a Cell growth is assessed with the xCELLigence system that measures electrical impedance across micro-electrodes integrated on the bottom of tissue culture E-96 plates. Impedance measurements are displayed as Cell Index (CI) values, providing real-time quantitative information on cell growth. The effect of the inhibitors on cell growth is calculated as $\mathrm{CI}_{\mathrm{DRUG}}$ /

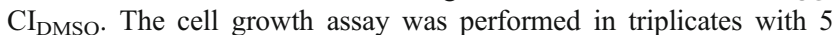
different concentrations $40 \mu \mathrm{M}, 20 \mu \mathrm{M}, 10 \mu \mathrm{M}, 5 \mu \mathrm{M}$, and $2.5 \mu \mathrm{M}$.

detected on the fusion protein of GSK $3 \alpha / \beta$ (data not shown). These data indicate a very low Akt activity in each cell line, evidence of a significant inhibition of the pathway by these inhibitory molecules in HCC cells.

Cytotoxic effect of drugs on HCC cells through apoptosis

It is a well-documented fact that the Akt pathway has an important anti-apoptotic role in different cells [22, 23]. Morphological changes specific to apoptosis can be observed quite early after apoptotic stimuli $[24,25]$. In order to see the morphological changes in Huh7, HepG2
Huh7-LY294002 (๔), Huh7-Akt Inhibitor VIII ( $-\infty)$, Huh7Wortmannin (-), Mahlavu-LY294002 (-), Mahlavu-Akt Inhibitor VIII (-), Mahlavu-Wortmannin (-). b Analysis of apoptosis associated morphological changes with light microscopy. Huh7 and Mahlavu cells were treated with the indicated inhibitors at 24 and 48 hours. Huh7 cells : LY294002 $(4 \mu \mathrm{M})$, Wortmannin $(26 \mu \mathrm{M})$, Akt Inhibitor VIII $(4.5 \mu \mathrm{M})$; Mahlavu cells : LY294002 $(7 \mu \mathrm{M})$, Wortmannin $(20 \mu \mathrm{M})$, Akt Inhibitor VIII $(10 \mu \mathrm{M})$. 20X pictures were taken with OLYMPUS CKX41 microscope with DP72 camera

and Mahlavu cells after treatment with each drug, cells were treated with inhibitors for 24 and $48 \mathrm{~h}$. Each drug was used at its IC50 value obtained after $24 \mathrm{~h}$ of treatment. Apoptotic cells usually exhibit extensive DNA cleavage during the early stages of this controlled cell death mechanism. Cleavage may produce double-stranded, low molecular weight DNA fragments as well as singlestranded high molecular weight DNA fragments that manifests themselves as condensed aberrant nuclei, as shown by DAPI (Fig. 4) and the Hoechst 33258 stain (data not shown). This observation demonstrated that those cells displayed the type of cell death that is specific to apoptosis. 
a

Huh7
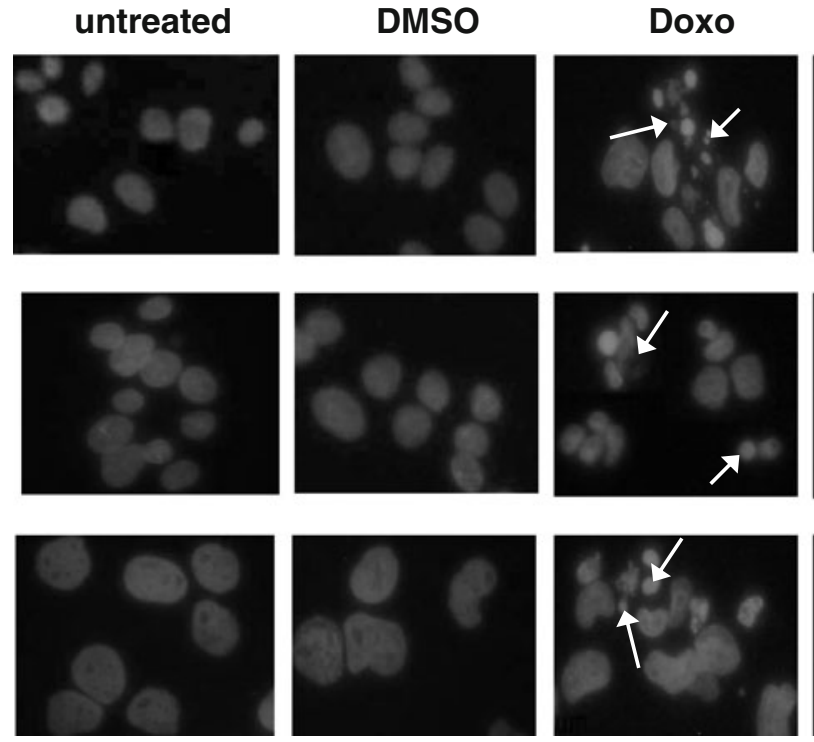

b
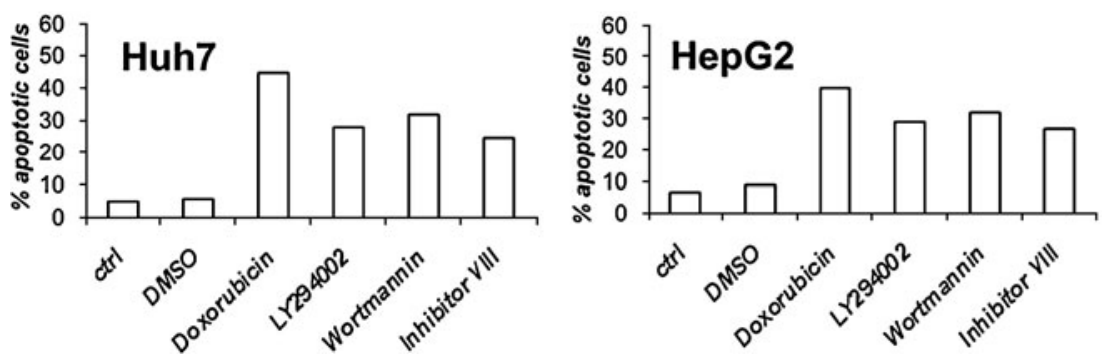

\section{LY294002}
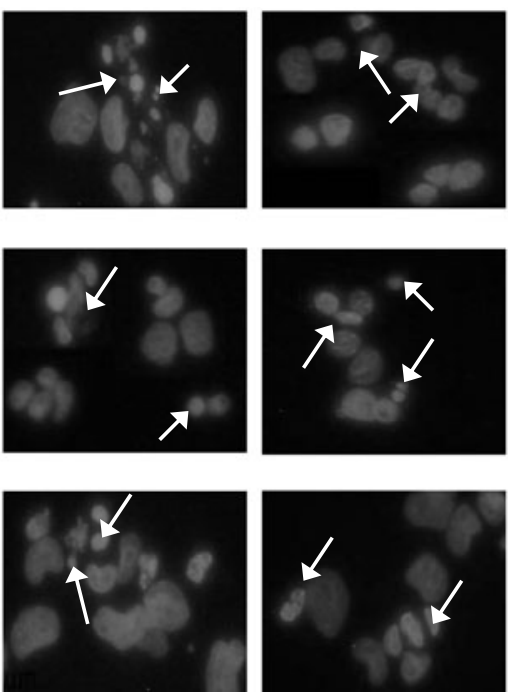
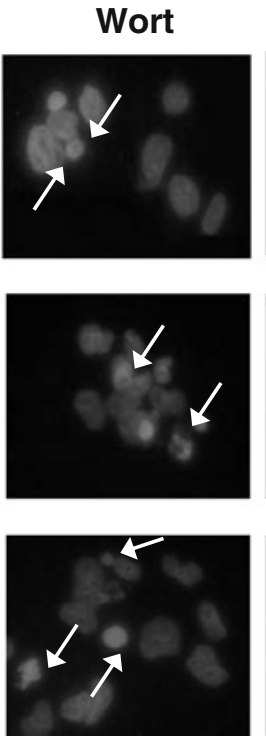

Inh VIII
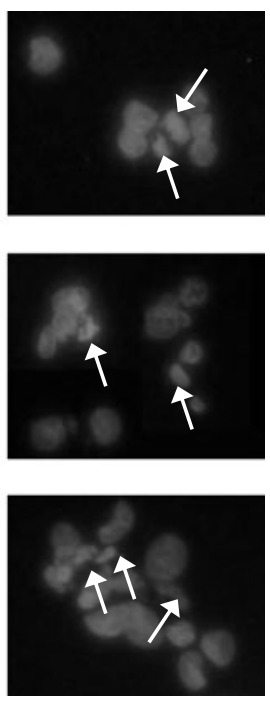

Fig. 4 DAPI staining showing the aberrant nuclear DNA due to the apoptotic cells with condensed nuclei (white arrows) in the presence of inhibitors with IC50 concentrations. a The pro-apoptotic effect of Akt pathway inhibitors on the morphology of the nuclear chromatin in HCC cells. Cells were treated for $24 \mathrm{~h}$ with the IC50 values (Huh7 : LY294002 (4 $\mu \mathrm{M})$, Wortmannin (26 $\mu \mathrm{M})$, Akt Inhibitor VIII (4.5 $\mu \mathrm{M})$; HepG2 : LY294002 (25 $\mu \mathrm{M})$, Wortmannin $(29 \mu \mathrm{M})$, Akt Inhibitor VIII (18 $\mu \mathrm{M})$; Mahlavu : LY294002 (7 $\mu \mathrm{M})$, Wortmannin $(20 \mu \mathrm{M})$, Akt Inhibitor VIII $(10 \mu \mathrm{M}))$, then fixed and stained with DAPI. No changes were induced by DMSO. All samples treated with the positive control, Doxorubicine (100 ng/ml) showed evident apoptotic nuclei. Well markable, even if less present, are apoptotic nuclei after apoptosis induction with each drug. The results were from one experiment representative of three experiments. Bar $=10 \mu \mathrm{m}$ b Apoptotic cells were quantified by counting a minimum of 4 fields containing at least 150 cells. The results are presented as the mean of three independent experiments. Doxorubicine, an inhibitor of enzyme topoisomerase II progression by intercalation of DNA, induced a marked percentage of apoptosis. The three inhibitors used in this study within each cell line, gave similar results. SD was less then $10 \%$
The pro-apoptotic effect of the drugs was assessed by counting aberrant nuclei in DAPI stained cells. The morphological features of apoptosis, i.e. condensation of chromatin and fragmentation of the nucleus, were examined. Control cells showed rounded and homogeneous nuclei, whereas drug treated-cells showed condensed and fragmented nuclei (Fig. 5a). The percentage of apoptosis ranged from $32 \%$ to $25 \%$ in Huh7, from $32 \%$ to $27 \%$ in HepG2 and from $35 \%$ to $28 \%$ in Mahlavu, (Fig. 4b).

In order to further clarify the type of cell death mechanism and the morphological changes that we observe in Figs. 3b, 4a, in the presence of the inhibitors as apoptosis, we performed Poly ADP-ribosyl polymerase (PARP) cleavage analysis by western blot. Huh7, HepG2 and Mahlavu cells were treated with each drug at the
24hours-IC50. PARP is typically cleaved from $113 \mathrm{kDa}$ to 89 and $24 \mathrm{kDa}$ fragments by caspase-3 during apoptosis. Although cleaved PARP is also detected during necrosis, the cleaved product's molecular size is different $(50 \mathrm{kDa})$. As shown in Fig. 5, the cleaved band $(89 \mathrm{kDa})$ is due to apoptosis, not necrosis [26]. Our observations clearly demonstrated that Akt pathway inhibitors had an apoptosis-dependent cytotoxic effect on HCC cell lines.

\section{Comparative analysis of PTEN in HCC cells}

With the aim of identifying differential responses of HCC cells to Akt pathway inhibitors, we further investigated PTEN, another pathway related molecule. PTEN protein expression in HCC cell lines exhibited differential expres- 


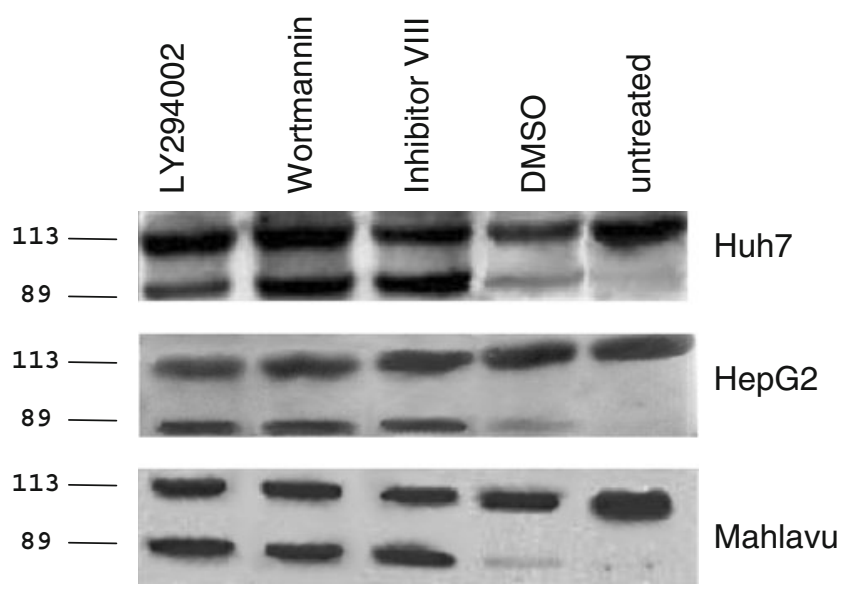

Fig. 5 Investigation of apoptotic cell death in the presence of Akt pathway inhibitors. Apoptosis activation was detected by means of PARP cleavage. The antibodies used recognize both the intact form $(113 \mathrm{KDa})$ and the cleaved one $(89 \mathrm{KDa})$. In each lane $20 \mu \mathrm{g}$ proteins were loaded. . Almost no cleavage is observable in control and DMSO-treated samples. An evident PARP cleavage is induced by the three inhibitors used. Each cell line induced similar PARP cleavage. Data were representative of three independent experiments

sion patterns, ranging from marked expression in the Huh7 and HepG2 cell lines, to the absence of PTEN expression in Mahlavu cell line. The absence of PTEN protein expression was in correlation with the hyperphosphorylation of Akt, higher kinase activity on exogenous GSK3 $\alpha / \beta$ fusion protein and on endogenous BAD protein in Mahlavu cell line. In correlation with the absence of PTEN protein expression, the Mahlavu cell line had mRNA expression with a partial deletion in the PTEN gene in exon 4 (Fig. 6), which may explain the lack of protein that results in the hyperactivation of the Akt protein in this cell line.

\section{Discussion}

In this study, we have shown hyperactivation of the Akt protein in hepatoma cell lines and apoptosis induction in time- and dose- dependent manners after treatment with three specific inhibitors of the PI3K/Akt pathway. The PI3K/Akt signaling pathway plays a significant role in carcinogenesis and drug resistance in different types of cancer including HCC, making Akt a potential target for cancer treatment $[28,29]$.

Tumors with activated PI3K/Akt signaling have been shown to become more aggressive, and Akt pathway activation has been identified as a significant risk factor for early disease recurrence and poor prognosis in HCC patients $[30,31]$. Activated Akt correlates also with local metastasis of tumor cells from the primary liver cancer into the circulatory system and the survival of the circulating cells without cell-substratum interaction [32], showing the significance of this hyperactivated pathway not only in liver tumor aggressiveness but also in tumor diffusion and survival in different environments. Therefore we initially examined total Akt protein and native p-Akt levels in HCC cell lines. Mahlavu cells were previously reported to be poorly differentiated when compared to the welldifferentiated "hepatocyte-like" Huh7 and HepG2 cells [18]. Although the cell lines included in this study showed similar total Akt protein expression (Fig. 1a), only Mahlavu cells displayed hyperphosphorylated Akt protein (Fig. 1a), which was determined by anti-p473Ser-Akt antibodies, because Ser473 Akt phosphorylation is a requirement for full Akt enzyme activity [33]. In Mahlavu cells, in parallel to the hyperphosphorylation of Akt, we also observed a lack of PTEN protein expression (Fig. 6) and increased phosphor-
Fig. 6 Differential expression of the PTEN gene in human HCC cell lines. a Whole-cell lysates $(40 \mu \mathrm{g})$ were analyzed by Western blotting using antiPTEN antibody. Mahlavu cell line has no PTEN expression. b PCR analysis of PTEN gene in HCC cell lines. Figure describes the loss of PTEN gene fragment. The gene fragment that is lacking is located within exon 4 and 5

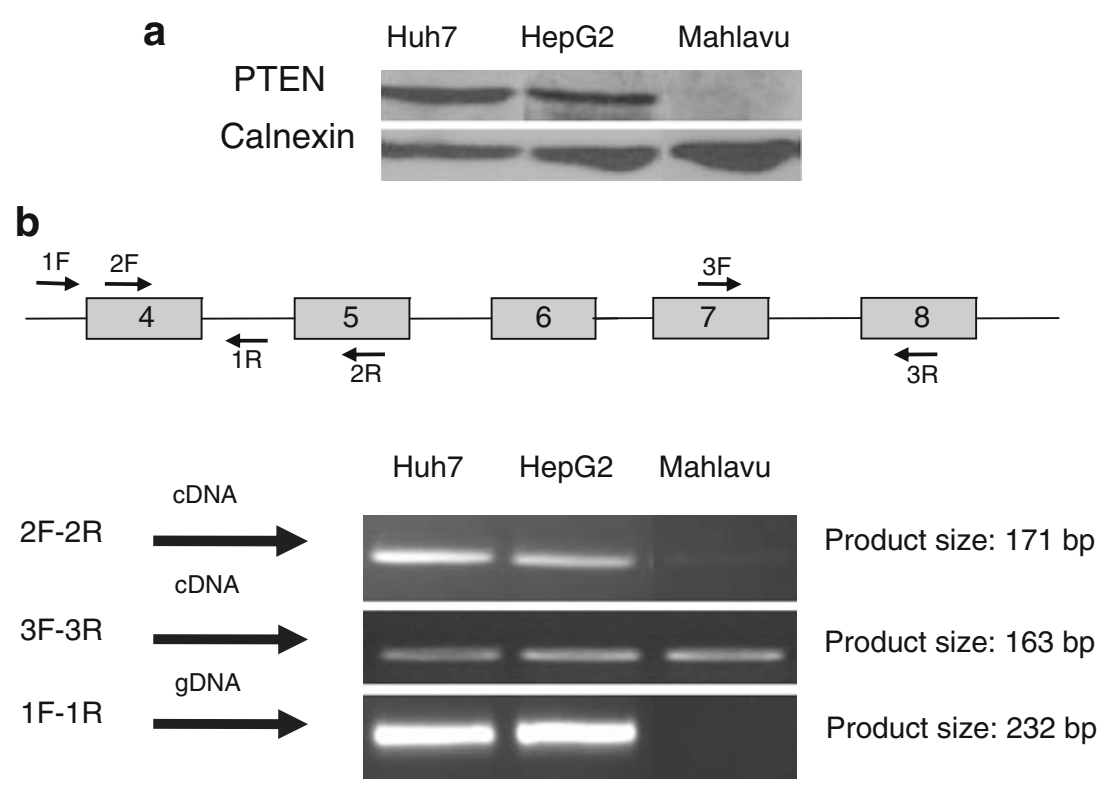


ylation of the downstream protein Bad on Ser136 and of the exogenous GSK3 substrate (Fig. $1 \mathrm{~b}$ and c).

The activation of PI3K/Akt signaling frequently related to PTEN mutation has also been observed in nearly $50 \%$ of HCC [34], suggesting the importance of this pathway, since tumors with hyperactive Akt due to PTEN loss depend on hyperactivated Akt signaling for growth and survival [10]. Indeed, our results support the observations that a PTEN deficient cell line Mahlavu has hyperactivated Akt protein. Moreover Mahlavu has the higher IC50 values for Wortmannin than well differentiated Huh7 and HepG2 cell lines.

The great majority of protein kinase inhibitors that have been developed, bind at or near the ATP binding site [35]. These compounds were recommended for use in a concentration range of 0,1 to $100 \mu \mathrm{M}$ to assess the roles of particular protein kinases. Depending on concentration, kinase inhibitors may act as multi-kinase inhibitors. Therefore in our study we analyzed the PI3K/Akt signaling inhibitors with concentrations between $40 \mu \mathrm{M}-2.5 \mu \mathrm{M}$ (Figs. 2 and 3) in order to identify their specific IC50 values on hepatoma cell lines. We think that with the concentration we used LY294002 and Wortmannin exhibit their cytotoxic activity through binding to the proximity of the active sites of their target kinases. Structural analysis of the p110 $\gamma$ isoform of PI3K in the presence of LY294002 demonstrated that this inhibitor binds to the active site. Cell death induced by LY294002 is through GSK3 $\beta$ activity, which is also demonstrated in the presence of lithium, a known inhibitor of GSK3 $\beta[36,37]$. Consistent with the structural similarity between the PI3K and mTOR kinase domains, LY294002 and Wortmannin act on both of these kinases with similar IC50 values [38]. Both PI3K and mTORC2 are the upstream proteins of the Akt pathway. Therefore, we focused also on the downstream analysis of Akt protein activation/inhibition regardless of the direct targets of LY294002 and Wortmannin in HCC cells. To stress the importance of Akt pathway signaling inhibition as a potential therapeutic target in liver cancer, we analyzed the effects of the selective Akt inhibitor, Akt Inhibitor VIII on HCC cells [20, 21].

We applied two different cytotoxicity assays, conventional NCI-60 method and novel RT-CES system. Both assays resulted in similar IC50 values for 24, 48, and $72 \mathrm{~h}$ for the specific PI3K/Akt signaling inhibitors LY294002, Wortmannin, and Akt inhibitor VIII, although it is possible to calculate IC50 for each time point with RT-CES. As expected, we were able to demonstrate that all three inhibitors had cytotoxic activity. At $24 \mathrm{~h}$ all three cells had comparable IC50s but with longer treatment times Mahlavu cells displayed higher IC50s when compared to Huh7 and HepG2 cells. RT-CES analysis demonstrated that normal cell growth has a cell index (CI) of around 1.2
(Fig. 3a). $20 \mu \mathrm{M}$ inhibitor treatment did not influence the cell proliferation during the initial $10-16 \mathrm{~h}$. The cytotoxic effect of the inhibitors became established toward the end of the $24 \mathrm{~h}$ (Fig. 3a, 40-10 $\mu \mathrm{M}$ ) as it can be observed by the CI of 0.5 . Between $36 \mathrm{~h}$ and to $60 \mathrm{~h}$ RT-CES data demonstrated whether they inhibit cell proliferation irreversibly or whether cells can survive afterwards. In the case of LY294002 and Akt inhibitor VIII, CI approached to 0.2 at the $60^{\text {th }}$ hour meaning almost no cells attached to the bottom of the cell culture plates to form colonies. We confirmed this data in parallel experiments by direct light microscopy visualization of the cells at 24 and $48 \mathrm{~h}$ (Fig. 3b). Cells treated with Wortmannin displayed a similar growth curve with CI during first $24 \mathrm{~h}$ to that of LY294002 and Akt inhibitor VIII did. However starting from $36 \mathrm{~h}$ both Huh7 and Mahlavu cells continued to proliferate and expanded to cover the bottom of the Eplate parallel to the DMSO treated control cells even with very high $(40 \mu \mathrm{M})$ concentrations. We confirmed again by microscopy that the cells presented a healthy morphology (Fig. 3b).

Continuous very low Cell Index data (0.2-0.3) with LY294002 and Akt inhibitor VIII treatments on the hepatoma cells were the indications of apoptotic cell death. In addition direct light microscopy visualization of the cell morphology showed that all the inhibitors induced apoptosis on hepatoma cells. From the above evidence the nature of the cell death exhibited in the presence of the PI3K/Akt signaling inhibitors LY294002, Wortmannin, and Akt inhibitor VIII was characterized as apoptosis (Figs. 4 and 5).

The three drugs, generated a PARP cleavage process on the HCC cell lines after being administered (Fig. 5). As shown above, the drugs appear to have similar apoptotic effects in all the cell lines tested. In addition, since PI3K-Class IIIs control autophagic proteolysis, we examined the possibility that the cytotoxic effect of these inhibitors might be through autophagy [27]. After $48 \mathrm{~h}$ of incubation with the three inhibitors we performed western blot analysis of autophagy related proteins BECN1 and p62 but did not observe any alterations that could be attributed to autophagy (data not shown).

This study suggests that targeting the PI3K/Akt signaling pathway provides a promising strategy for designing molecular targeted therapy in the case of solid tumors, especially HCC. Our data also suggest that PI3K/Akt activation status serve as a biomarker for identifying candidate patients for treatment with inhibitors of PI3K and/or of its downstream targets. However, it should be noted that drug transporters or IAPs (Inhibitors of Apoptosis Proteins) could contribute to the therapeutic resistance. Likewise, transcription factors, such as NF- $\mathrm{KB}$, can upregulate transporters like MRP2 to induce multidrug resistance in HCC [39]. Furthermore, we have previously 
shown that during liver tumorigenesis HCC cells develop a "survivor phenotype" independent of the cause of oncogenic transformation under oxidative stress conditions [40].

It may also be important to raise questions about the stability of the drugs for longer treatments. We performed experiments, by monitoring cell growth real time, that demonstrated that when drug concentration increases, growth inhibition lasts longer. This observation could be due to a lower a decay rate of active drug molecule concentration. Our results obtained by the three PI3K/Akt pathway inhibitors used clearly demonstrated that the Akt pathway can still be a target when Akt and BAD are hyperphosphorylated and the PTEN protein is impaired, as we show in the Mahlavu cell line. In treatment, chemotherapeutic agents are usually given in a protocol with repeating dosages to target resistant cell populations.

Tumors with hyperactive Akt due to PTEN loss depend on Akt signaling for growth and survival [10]. Activated Akt pathway confers resistance to cancer therapy, making Akt a promising target for cancer treatment [34]. Increasing knowledge in the molecular mechanisms underlying hepatocarcinogenesis and the advent of molecular targeted therapies provide a promising treatment approach for HCC patients. Novel therapeutic targets, molecular oncogenic mechanisms and signaling cascades responsible for tumor growth should be investigated together with potential chemotherapeutic agents to improve clinical efficacy.

Acknowledgement We are indebted to Prof A. Esen (Virgina Tech) and Ms. R. Nelson for editing the English of the final version of our manuscript. This work was supported by The Scientific and Technical Research Council of Turkey, TUBITAK (project \# 106 S359), the KANILTEK project Bilkent University local funds and MAE 2008, Fondazione CARIFE, Italian MIUR Cofin 2005, Fondazione CARICENTO, local funds of Ferrara University for Stamina Project (to $\mathrm{SC}), \mathrm{LMN}$ and DE.

\section{References}

1. McGlynn KA, Tsao L, Hsing AW, Devesa SS, Fraumeni JF Jr (2001) International trends and patterns of primary liver cancer. Int J Cancer 94:290-296. doi:10.1002/ijc.1456

2. Ozturk N, Erdal E, Mumcuoglu M, Akcali KC, Yalcin O, Senturk S, Arslan-Ergul A, Gur B, Yulug I, Cetin-Atalay R, Yakicier C, Yagci T, Tez M, Ozturk M (2006) Reprogramming of replicative senescence in hepatocellular carcinoma-derived cells. Proc Natl Acad Sci USA 103:2178-2183. doi:10.1073/pnas.0510877103

3. Osaki M, Oshimura M, Ito H (2004) PI3K-Akt pathway: its functions and alterations in human cancer. Apoptosis 9:667-676. doi:10.1023/B:APPT.0000045801.15585.dd

4. Llovet JM, Ricci S, Mazzaferro V, Hilgard P, Gane E et al (2008) Sorafenib in advanced hepatocellular carcinoma. N Engl J Med 359:378-390. doi:10.1056/NEJMoa0708857

5. Engelman JA (2009) Targeting PI3K signalling in cancer: opportunities, challenges and limitations. Nat Rev Cancer 9:550-562. doi:10.1038/nrc2664
6. Liu P, Cheng H, Roberts TM, Zhao JJ (2009) Targeting the phosphoinositide 3-kinase pathway in cancer. Nat Rev Drug Discov 8:627-644. doi:10.1038/nrd2926

7. Tokunaga E, Oki E, Egashira A, Sadanaga N, Morita M, Kakeji Y, Maehara Y (2008) Deregulation of the Akt pathway in human cancer. Curr Cancer Drug Targets 8:27-36

8. Carnero A, Blanco-Aparicio C, Renner O, Link W, Leal JF (2008) The PTEN/PI3K/AKT signalling pathway in cancer, therapeutic implications. Curr Cancer Drug Targets 8:187-198

9. Hanada M, Feng J, Hemmings BA (2004) Structure, regulation and function of $\mathrm{PKB} / \mathrm{AKT}-\mathrm{a}$ major therapeutic target. Biochim Biophys Acta 1697:3-16. doi:10.1016/j.bbapap.2003.11.009

10. Salvesen HB, Stefansson I, Kretzschmar EI, Gruber P, MacDonald ND, Ryan A, Jacobs IJ, Akslen LA, Das S (2004) Significance of PTEN alterations in endometrial carcinoma: a population-based study of mutations, promoter methylation and PTEN protein expression. Int J Oncol 25:1615-1623

11. Xu G, Zhang W, Bertram P, Zheng XF, McLeod H (2004) Pharmacogenomic profiling of the PI3K/PTEN-AKT-mTOR pathway in common human tumors. Int J Oncol 24:893-900

12. Arcaro A, Guerreiro AS (2007) The phosphoinositide 3-kinase pathway in human cancer: genetic alterations and therapeutic implications. Curr Genomics 8:271-306. doi:10.2174/138920 207782446160

13. Ozturk M EE, Ozturk N, Cetin-Atalay R and Irmak B (2005) Molecular Biology of Liver Cancer. In: RA M. Encyclopedia of Molecular Cell Biology and Molecular Medicine, Wiley-VCH, 2ed, vol. 7:323-335

14. Missiroli S, Etro D, Buontempo F, Ye K, Capitani S, Neri LM (2009) Nuclear translocation of active AKT is required for erythroid differentiation in erythropoietin treated K562 erythroleukemia cells. Int J Biochem Cell Biol 41(3):570-577

15. Monks A, Scudiero D, Skehan P, Shoemaker R, Paull K, Vistica D, Hose C, Langley J, Cronise P, Vaigro-Wolff A et al (1991) Feasibility of a high-flux anticancer drug screen using a diverse panel of cultured human tumor cell lines. J Natl Cancer Inst 83:757-766

16. Kirstein SL, Atienza JM, Xi B, Zhu J, Yu N, Wang X, Xu X, Abassi YA (2006) Live cell quality control and utility of real-time cell electronic sensing for assay development. Assay Drug Dev Technol 4(5):545-553

17. LoPiccolo J, Granville CA, Gills JJ, Dennis PA (2007) Targeting Akt in cancer therapy. Anticancer Drugs 18(8):861874, Review

18. Sayan B, Tolga Emre NC, Irmak MB, Ozturk M, Cetin-Atalay R (2009) Nuclear exclusion of p33ING1b tumor suppressor protein: explored in HCC cells using a new highly specific antibody. Hybridoma 28:1-6. doi:10.1089/hyb.2008.0058

19. del Peso L, Gonzalez-Garcia M, Page C, Herrera R, Nunez G (1997) Interleukin-3-induced phosphorylation of BAD through the protein kinase Akt. Science 278:687-689

20. Barnett SF, Defeo-Jones D, Fu S, Hancock PJ, Haskell KM et al (2005) Identification and characterization of pleckstrin-homologydomain-dependent and isoenzyme-specific Akt inhibitors. Biochem J 385:399-408. doi:10.1042/BJ20041140

21. Zhao Z, Leister WH, Robinson RG, Barnett SF, Defeo-Jones D, Jones RE, Hartman GD, Huff JR, Huber HE, Duggan ME, Lindsley CW (2005) Discovery of 2, 3, 5-trisubstituted pyridine derivatives as potent Akt1 and Akt2 dual inhibitors. Bioorg Med Chem Lett 15:905-909. doi:10.1016/j.bmcl.2004.12.062

22. Manning BD, Cantley LC (2007) AKT/PKB signaling: navigating downstream. Cell 129:1261-1274. doi:10.1016/j.cell.2007.06.009

23. Fabregat I (2009) Dysregulation of apoptosis in hepatocellular carcinoma cells. World J Gastroenterol 15:513-520

24. Kim MJ, Oh SJ, Park SH, Kang HJ, Won MH, Kang TC, Hwang IK, Park JB, Kim JI, Kim J, Lee JY (2007) Hypoxia-induced cell 
death of HepG2 cells involves a necrotic cell death mediated by calpain. Apoptosis 12:707-718. doi:10.1007/s10495-006-0002-3

25. Messam CA, Pittman RN (1998) Asynchrony and commitment to die during apoptosis. Exp Cell Res 238:389-398. doi:10.1006/ excr.1997.3845

26. Gobeil S, Boucher CC, Nadeau D, Poirier GG (2001) Characterization of the necrotic cleavage of poly(ADP-ribose) polymerase (PARP-1): implication of lysosomal proteases. Cell Death Differ 8:588-594. doi:10.1038/sj.cdd.4400851

27. Blommaart EF, Krause U, Schellens JP, Vreeling-Sindelarova H, Meijer AJ (1997) The phosphatidylinositol 3-kinase inhibitors wortmannin and LY294002 inhibit autophagy in isolated rat hepatocytes. Eur J Biochem 243:240-246

28. Cully M, You H, Levine AJ, Mak TW (2006) Beyond PTEN mutations: the PI3K pathway as an integrator of multiple inputs during tumorigenesis. Nat Rev Cancer 6(3):184-192, Review

29. Schmitz KJ, Wohlschlaeger J, Lang H, Sotiropoulos GC, Malago $M$ et al (2008) Activation of the ERK and AKT signalling pathway predicts poor prognosis in hepatocellular carcinoma and ERK activation in cancer tissue is associated with hepatitis $\mathrm{C}$ virus infection. J Hepatol 48:83-90. doi:10.1016/j.jhep.2007.08.018

30. Nakanishi K, Sakamoto M, Yamasaki S, Todo S, Hirohashi S (2005) Akt phosphorylation is a risk factor for early disease recurrence and poor prognosis in hepatocellular carcinoma. Cancer 103(2):307-312

31. $\mathrm{Hu}$ TH, Huang CC, Lin PR, Chang HW, Ger LP, Lin YW, Changchien CS, Lee CM, Tai MH (2003) Expression and prognostic role of tumor suppressor gene PTEN/MMAC1/TEP1 in hepatocellular carcinoma. Cancer 97(8):1929-1940

32. Boyault S, Rickman DS, de Reynies A, Balabaud C, Rebouissou S, Jeannot E, Herault A, Saric J, Belghiti J,
Franco D (2007) (2008) Transcriptome classification of HCC is related to gene alterations and to new therapeutic targets. Hepatology 45:42-52

33. Recher C, Dos Santos C, Demur C, Payrastre B (2005) mTOR, a new therapeutic target in acute myeloid leukemia. Cell Cycle 4:1540-1549

34. Lindsley CW, Barnett SF, Layton ME, Bilodeau MT (2008) The $\mathrm{PI} 3 \mathrm{~K} / \mathrm{Akt}$ pathway: recent progress in the development of ATPcompetitive and allosteric Akt kinase inhibitors. Curr Cancer Drug Targets 8:7-18

35. Bain J, Plater L, Elliott M, Shpiro N, Hastie CJ, McLauchlan H, Klevernic I, Arthur JS, Alessi DR, Cohen P (2007) The selectivity of protein kinase inhibitors: a further update. Biochem J 408:297315. doi:10.1042/BJ20070797

36. Beurel E, Kornprobst M, Blivet-Van Eggelpoel MJ, Cadoret A, Capeau J, Desbois-Mouthon C (2005) GSK-3beta reactivation with LY294002 sensitizes hepatoma cells to chemotherapyinduced apoptosis. Int J Oncol 27:215-222

37. Erdal E, Ozturk N, Cagatay T, Eksioglu-Demiralp E, Ozturk M (2005) Lithium-mediated downregulation of PKB/Akt and cyclin $\mathrm{E}$ with growth inhibition in hepatocellular carcinoma cells. Int $\mathrm{J}$ Cancer 115:903-910. doi:10.1002/ijc.20972

38. Ballou LM, Selinger ES, Choi JY, Drueckhammer DG, Lin RZ (2007) Inhibition of mammalian target of rapamycin signaling by 2-(morpholin-1-yl)pyrimido[2, 1-alpha]isoquinolin-4-one. J Biol Chem 282:24463-24470. doi:10.1074/jbc.M704741200

39. Okamoto T, Sanda T, Asamitsu K (2007) NF-kappa B signaling and carcinogenesis. Curr Pharm Des 13:447-462

40. Irmak MB, Ince G, Ozturk M, Cetin-Atalay R (2003) Acquired tolerance of hepatocellular carcinoma cells to selenium deficiency: a selective survival mechanism? Cancer Res 63:6707-6715 